The Israeli Journal of Aquaculture - IJA.73.2021.1115060, 13 pages

CCBY-NC-ND-4.0 • https://doi.org/10.46989/001c.19033

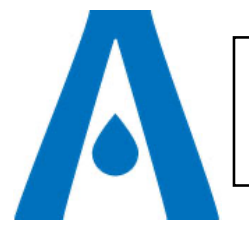

Produced by the AquacultureHub, a non-profit foundation

The IJA is an Open-Access, scientific journal

Sale of IJA articles is strictly forbidden

\title{
Effects of acute low salinity stress on the liver structure, physiology and biochemistry of juvenile Chinese sea bass (Lateolabrax maculatus)
}

\author{
Yukai Yang ${ }^{1,2}$, Wei Yu1,2, Heizhao Lin ${ }^{1,2 *}$, Hu Shu ${ }^{3}$, \\ Xiaolin Huang ${ }^{1,2}$, Tao $\mathrm{Li}^{1,2}$, Zhong Huang ${ }^{1,2}$, Pengfei Wang ${ }^{1}$, Qianqian \\ Huang ${ }^{1,4}$, Pengwei Xun ${ }^{1,4}$ \\ ${ }^{1}$ Key Lab of South China Sea Fishery Resources Exploitation \&Utilization, Ministry of \\ Agriculture and Rural Affairs; Guangdong Provincial Key Laboratory of Fishery Ecology and \\ Environment; South China Sea Fisheries Research Institute, Chinese Academy of Fishery \\ Science, Guangzhou 510300, China; \\ 2 Shenzhen Base of South China Sea Fisheries Research Institute, Chinese Academy of Fishery \\ Sciences, Shenzhen 518121, China; \\ 3 School of Life Science, Guangzhou University, Guangzhou 510006, China; \\ ${ }^{4}$ College of Fisheries and Life Sciences, Shanghai Ocean University, Shanghai 201506, China)
}

Key words: Lateolabrax maculatus; salinity stress; liver structure; oxidative stress; non-specific immunity

\begin{abstract}
In order to explore the effects of acute low salinity stress on the liver structure, physiology and biochemistry of the larvae of Lateolabrax maculatus, the experiment was carried out to transfer the juveniles direct from salinity $30 \%$ (control group) to salinity $20 \%, 10 \%$, and $0 \%$, respectively. Changes in liver microstructure and related physiological and biochemical indexes at different time points were observed. The results showed that no fish died during the whole experiment and all of them returned to normal behavior within 15 minutes. The liver cells of juvenile Chinese sea bass showed pathological changes such as swelling, vacuolation and nuclear pyknosis after low salinity stress, and the lower the salinity, the earlier the abnormal phenomenon appeared. The total antioxidant capacity (T-AOC) and superoxide dismutase (SOD) of liver showed a rapid increase and then decrease; The level of malondialdehyde (MDA) returned to normal after high fluctuations. The activity of lysozyme (LZM) in experimental groups were higher than that in control group between $12 \mathrm{~h}$ and $48 \mathrm{~h}$, while there was not significantly different before $6 \mathrm{~h}$ in each group $(P>0.05)$, all of them returned to normal in $96 \mathrm{~h}$. The activity of alkaline phosphatase (ALP) and acid phosphatase (ACP) increased firstly and then decreased during the time of stress, and there was no significant difference between each group at the same time point $(P>0.05)$. The comprehensive analysis showed that the juvenile Chinese sea bass had strong osmotic pressure regulation ability, and the acute low salinity stress had little effect on the liver structure and physiological and biochemical indexes.
\end{abstract}

\footnotetext{
* Corresponding author: Heizhao Lin, e-mail: linheizhao@163.com
} 


\section{Introduction}

Salinity is one of the critical environmental factors affecting the survival and growth of fish. Fish (especially euryhaline fishes) have osmoregulation abilities. When sudden changes in the external ecological salinity occur, they cause adaptive changes of related enzyme activities, tissue structure, and gene expression levels (Sun et al., 2017).

The liver is the largest digestive gland of the fish, it can secrete bile to promote the decomposition and absorption of fat and also involved in the synthesis, storage, metabolism, transformation and decomposition of various substances. Liver cells include glycogen, lipid droplets and pigments, its content is closely related to the physiological state of the body. During acute stress, the liver structure will change to maintain homeostasis, absorption and energy conversion efficiency (Ou et al., 2018). Liver is also a main tissue with oxidation reactions in fishes, it has a large number of antioxidant enzymes such as superoxide dismutase (SOD) and catalase (CAT), as well as acid phosphatase (ACP) and alkaline phosphatase (AKP), lysozyme (LSZ) and other enzymes related to non-specific immunity, these enzymes play an important role in the immune response of fish after environmental stress (Cui et al., 2017).

The Chinese sea bass (Lateolabrax maculatus) is commonly known as sea bass, it belongs to Perciformes, Serranidae, and Lateolabrax. It is widely distributed in China, Korean Peninsula and the coast of Japan. The Chinese sea basses are delicious, nutritious, fast-growing, and have wide adaptability to temperature and salinity. They are one of the important aquaculture fishes in China. In 2019, the national aquaculture production reached 180,200 tons (2020 China Fishery Statistical Yearbook). With the continuous expansion of the demand for Chinese sea bass, various breeding models have been widely promoted. At present, the largest Chinese sea bass breeding model in China is desalination breeding pattern and the largest producing area is the city of Zhuhai, in where fish are farmed in desalination ponds, the growth rate is one third faster than that of mariculture when the salinity was close to $0 \%$ (Liang et al., 2015). In spite of this, the desalination technology of Chinese sea bass has not formed a unified norm so far, and the desalination will certainly cause fish fry stress and eventually death. This paper explores the effects of low salinity stress on the liver structure and related physiological and biochemical indexes of juvenile Chinese sea bass by designing desalinate experiments. The aim of this research is to provide aquafarmers with an efficient and applicable desalination protocol.

\section{Experimental materials}

\section{Materials and Methods}

The experimental Chinese sea basses were purchased from Zhaoan, Fujian Province, with a total length of $(5.41 \pm 0.61) \mathrm{cm}$ and body weight of $(1.61 \pm 0.31) \mathrm{g}$. At Shenzhen Base of South China Sea Fisheries Research Institute, fish breeding took place in natural seawater (salinity: 30\%o), and they were held for 2 weeks and then split into experimental groups. The experimental water was prepared by mixing the treated natural seawater and the mountain spring water into different salinities. After full aeration, the constant water temperature was $18{ }^{\circ} \mathrm{C}$, the $\mathrm{pH}$ was $8.0-8.2$, and the dissolved oxygen was not less than $6 \mathrm{mg} / \mathrm{L}$.

\section{Experimental design}

The culture container used in the experiment was a $500 \mathrm{~L}$ tank, four experimental groups named S30, S20, S10, and S0 were designed, and the salinity was adjusted to $30 \%$ (control), 20\%o, 10\%o, and 0\%, respectively. Each group was set to 3 replicates, totaling 12 tanks. At the beginning of the experiment, the holding 
experimental fishes were directly transferred into each experimental group's breeding tanks at a density of 60 per tank. Sampling was performed at 7-time points: $1 \mathrm{~h}, 3 \mathrm{~h}$, $6 \mathrm{~h}, 12 \mathrm{~h}, 24 \mathrm{~h}, 48 \mathrm{~h}$, and $96 \mathrm{~h}$, and the mortality of each group were registered before each sampling. 6 samples were randomly sampled per tank, anesthetized, dissected, and took out the livers, 3 of them stored in Bouin's fixative for tissue sectioning, another 3 stored in liquid nitrogen and then transferred to $-80^{\circ} \mathrm{C}$ for future enzyme activity detection. No feeding or water changing during the experiment.

\section{Sample determination}

The liver was preserved in Bouin's fixative solution, dehydrated by ethanol, dissolved in xylene, and embedded in paraffin. The liver was then cut into frozen slices, $5 \mu \mathrm{m}$ thick by a freezing microtome (Leica CM1850). The sections were then sealed with HE staining neutral resin, observed, and photographed under a biological microscope (Olympus CX43). $0.2-0.3 \mathrm{~g}$ liver samples were stored at $-80^{\circ} \mathrm{C}$ in sterile tubes, pulverized, and homogenized in an ice bath. Nine times the volume of normal saline was added to the homogenate, centrifuged at $4^{\circ} \mathrm{C}$ for $10 \mathrm{~min}(2500 \mathrm{r} / \mathrm{min})$, and the supernatant was used for enzyme activity measurement.

The relevant enzyme activities were tested using kit which produced by Nanjing Jiancheng Institute of Bioengineering. The protein content was determined by Coomassie Brilliant Blue method. Superoxide dismutase (SOD) was determined by xanthine oxidase method in $\mathrm{U} / \mathrm{mg}$; the total antioxidant capacity (T-AOC) was determined by Fluorescence Recovery after Photobleaching (FRAP) method, as $\mathrm{mmol} / \mathrm{g}$. Malondialdehyde (MDA) was determined by thiobarbituric acid (TBA) colorimetric method in $\mathrm{nmol} / \mathrm{mg}$. Lysozyme (LZM) was determined by turbidimetry in $\mathrm{U} / \mathrm{mg}$. Alkaline phosphatase (ALP), acidphosphatase (ACP) was determined by phenyldiphenyl phosphate method in king unit/g.

\section{Data Analysis}

The experimental data were processed by Excel 2007, and statistical analysis was performed by SPSS 17.0. The obtained data are expressed as mean \pm standard deviation (Mean \pm S.D.), with $P<0.05$ indicating their statistically significant differences.

\section{Results}

Effects of acute low salinity on behavior and survival rate of juvenile Chinese sea bass

After the juvenile Chinese sea basses were transferred from the salinity $30 \%$ into the water of all other experimental groups, they settled into the bottom of the tank first, then swam fast along the tank wall, and the frequency of gill movement was accelerated. In groups S20 and S10 they returned to normal swimming after 3-5 min. In the S0 group they returned to a normal activity after $15 \mathrm{~min}$. The survival rate in all replicates was $100 \%$ (Table $\mathbf{1}$ ).

Table 1 Mortality of $L$. maculatus juveniles under different salinities

\begin{tabular}{llllllll}
\hline \multicolumn{7}{c}{ Mortality $\%$} & \\
$96 h$ & $48 h$ & $24 h$ & $12 h$ & $6 h$ & $3 h$ & $1 h$ & Group \\
0 & 0 & 0 & 0 & 0 & 0 & 0 & S30 \\
0 & 0 & 0 & 0 & 0 & 0 & 0 & S20 \\
0 & 0 & 0 & 0 & 0 & 0 & 0 & S10 \\
0 & 0 & 0 & 0 & 0 & 0 & 0 & So \\
\hline
\end{tabular}

The Israeli Journal of Aquaculture - Bamidgeh • IJA.73.2021.1115060 
Effects of acute low salinity on liver structure of juvenile Chinese sea bass

The effect of acute low salinity stress on the liver structure of juvenile fish is shown in Figure 1. In the control group S30, veins and hepatic blood sinuses were more developed, and the liver plate cells were arranged radially around the central vein. The shape of hepatocyte was polygonal or nearly circular, cell boundaries were clear and closely arranged. The nucleus was large, median or deviation, deep stained with a clear nucleus. A small number of nuclei were condensed or dissolved, less vacuolization. There was no significant change in the tissue structure in relation to increasing salinity stress (Figure 1-A).

After $1 \mathrm{~h}$ of salinity stress in S20, the cell boundary was clear, the nucleus appeared blurred or dissolved, few cells were vacuolated. Hepatic veins, hepatic sinusoids and blood cells were abundant (Figure 1-B). As the salinity stress time prolonged, the cell began to swell and expand, and the shape was deformed. A small number of cells fused, more nuclei dissolved, more vacuolization. There were only a few clear nuclei at $6 \mathrm{~h}$ (Figure 1-C). By the $12 \mathrm{~h}$, the cell boundaries gradually became clear, and more nuclei returned to a clear state. There were still a few condensed nuclei, and a few cells were vacuolated. At 24-96 h after stress, the cell boundaries were clearer, the nucleus staining deepened, and the nucleolus was clear (Figure 1-D).

In the S10 group, the hepatocyte boundaries were blurred after $1 \mathrm{hrs}$, and more nuclei were blurred or dissolved. A small number of dissolved cells formed vacuoles (Figure 1-E). After 6 hrs., hepatic vacuolization was increased, and the nucleus pyknosis or lysis was more serious. Only a few clear nuclei could be seen at this time, cells fused in some areas, and the hepatic sinuses contracted and decreased (Figure 1-F). With time, the phenomenon of vacuolization, nucleus pyknosis and lysis gradually decreased. After $24 \mathrm{hrs}$, the cell boundary returned to a clearer state, the nucleus was clear, and the nucleolus was seen in the middle or partial position. Only a small number of nuclei were dissolved and a small number of hepatocytes were vacuolated. More hepatic sinuses and more deeply stained blood cells appeared at this moment (Figure 1-G). After 96 hrs, the hepatocyte boundary was clearer, the cytoplasmic staining was shallower, the hepatic sinusoids returned to normal, some of the nucleus was dissolved, and more vacuolation happened (Figure 1-H).

Cells in group S0 were swelled, deformed and disordered after $1 \mathrm{~h}$ of stress. Many nuclei were hyperpigmented with clear nucleoli, some nucleoli dissolved away. The venous constriction makes its lumen smaller. There were few hepatic sinuses could be seen at this time. (Figure 1-I). After 3 hrs, the cell boundaries gradually became blurred. In many cells, the cytoplasm was stained lightly or vacuolated, the nuclei were displaced. The hepatic sinuses were still rare, and the hepatic lamina structure was no longer clear (Figure 1-J). At $6 \mathrm{~h}$ after stress, the cells were arranged in disorder, but the cell boundaries became clear, the nuclei were deeply stained, and the nucleolus was clear. The nuclear lysis and cytoplasmic vacuolization were reduced, the cytoplasmic staining was deepened, and the hepatic sinusoids were increased (Figure $\mathbf{1 - K}$ ). With time, the venous cavity enlarged and the number of internal blood cells increased. By the $96 \mathrm{~h}$, the liver cells were polygonal with closely arranged, the boundary was clear. The nucleus was deeply stained and the nucleolus was clear. A few nuclei condensed or dissolved disappeared (Figure 1-L). 


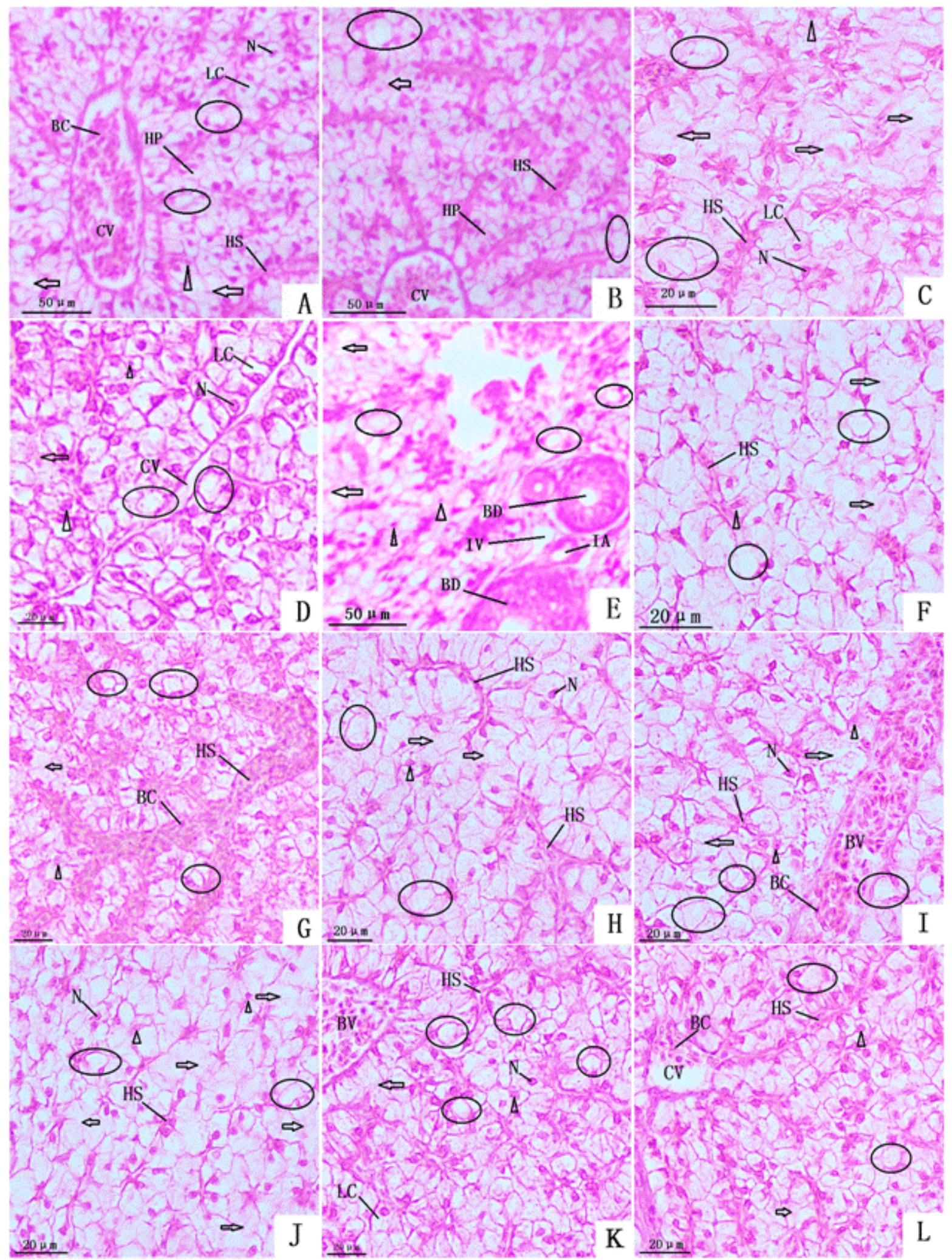

Figure 1 Effect of acute low salinity on histological structure of the liver of juvenile $L$. maculatus 
Note: CV means central vein, BC means blood cells, HS means hepatic sinusoid, HP means hepatic plate, LC means liver cell, $\mathrm{N}$ means nucleus, BV means blood vessel, BD means bile duct, IA means interlobular artery, IV means interlobular veins. The circle respresent vacuolations, arrows represent cell fusions, triangles represent pyknosis. The sampling time and groups of Figure 1 A-L are $96 \mathrm{~h}(\mathrm{~S} 30), 1 \mathrm{~h}(\mathrm{~S} 20), 6 \mathrm{~h}(\mathrm{~S} 20), 96 \mathrm{~h}(\mathrm{~S} 20), 1 \mathrm{~h}(\mathrm{~S} 10), 6 \mathrm{~h}(\mathrm{~S} 10)$, $24 \mathrm{~h}(\mathrm{~S} 10), 96 \mathrm{~h}(\mathrm{~S} 10), 1 \mathrm{~h}(\mathrm{~S} 0), 3 \mathrm{~h}(\mathrm{~S} 0), 6 \mathrm{~h}(\mathrm{~S} 0), 96 \mathrm{~h}(\mathrm{~S} 0)$ respectively.

Effects of acute low salinity stress on oxidative stress in the liver of juvenile Chinese sea bass

The activity of T-AOC in each group increased first and then decreased with the prolongation of stress time. It decreased to the lowest level at $96 \mathrm{~h}$. The peaks of oxidative stress in S30 and S20 followed at $12 \mathrm{~h}$, and low salinity S10 and S10 at 24 h. After $12 \mathrm{~h}$, the activity of T-AOC in S20 was significantly higher than that in S0 $(P<0.05)$. At other time points, the differences were not significant in the other groups $(P>0.05)$ (Figure 2-A).

With the prolongation of stress time, SOD activity in S30 and S10 groups showed an M-type fluctuation trend. The two peaks of S30 transpired at $3 \mathrm{~h}$ and $48 \mathrm{~h}$ respectively, and the two peaks of S10 happened respectively after $3 \mathrm{~h}$ and $24 \mathrm{~h}$. In group S20, the only peak followed at $12 \mathrm{~h}$, with the value of $141.48 \mathrm{U} / \mathrm{mg}$, which was significantly higher than that of S10 and S0 $(P<0.05)$. The peak of S0 happened at $48 \mathrm{~h}$ after stress, which was significantly higher than that of $\mathrm{S} 10(P<0.05)$ (Figure 2-B).

The MDA content in all experimental groups returned to normal after fluctuations as stress time goes on, with the peaks occurred at $48 \mathrm{~h}$ in groups S20 and S10, and 24 $\mathrm{h}$ in group S0 respectively. In the control group of S30, the MDA content showed a significantly higher value at $24 \mathrm{~h}$ and $96 \mathrm{~h}$ time points $(P<0.05)$, while stayed lower levels at other times $(P>0.05)$ (Figure 2-C). 

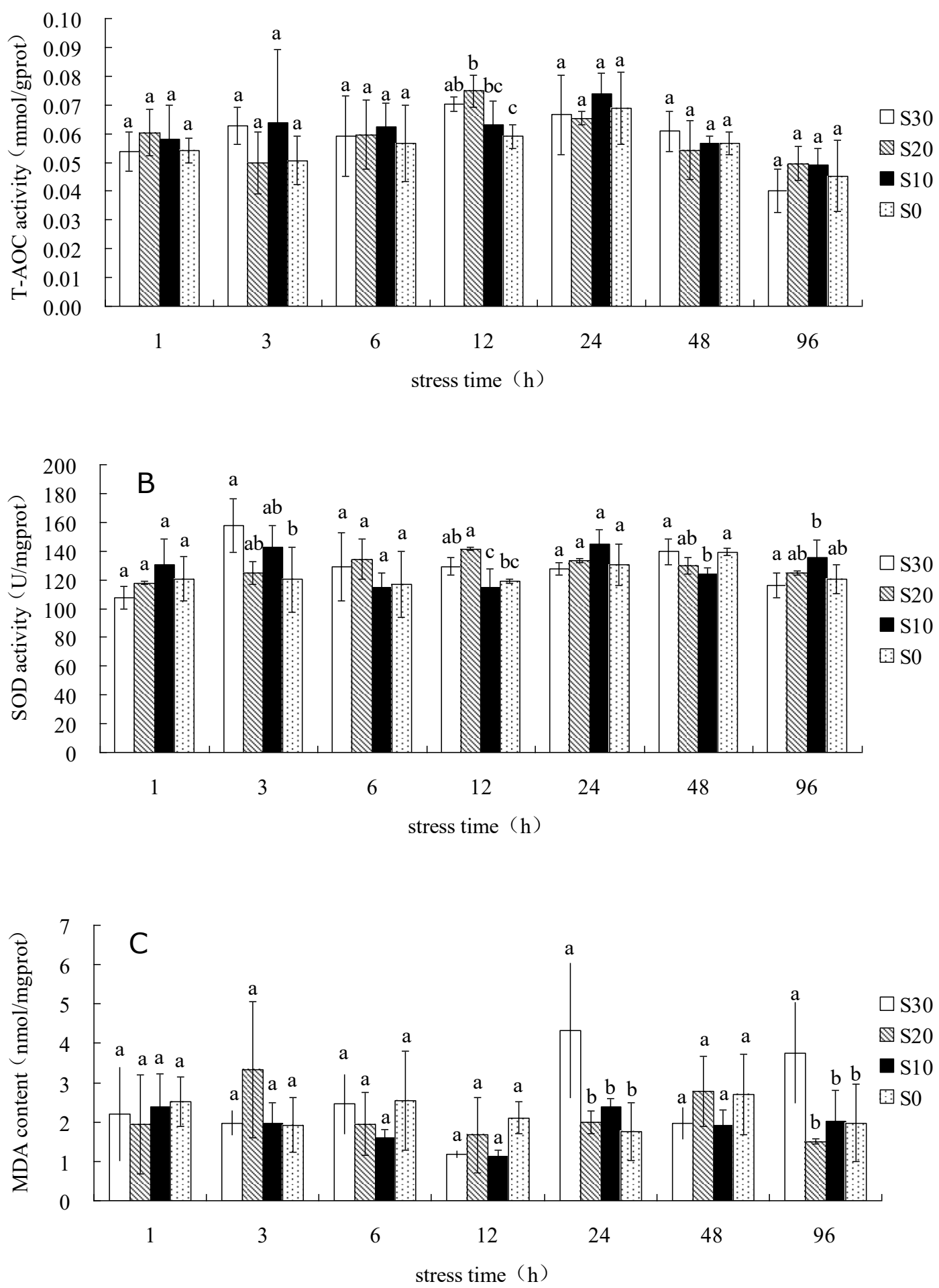

Figure 2 Effect of acute low salinity stress on oxidative stress on liver of juvenile L. maculates Note: Different letters in the same stress time indicate significant differences between groups ( $\mathrm{P}<0.05)$, the same below. 
Effects of acute low salinity stress on liver non-specific immunity in juvenile Chinese sea bass

The LZM activity of each group showed a trend of increasing first and then decreasing with time, with the peaks occurred at $3 \mathrm{~h}$ (S30), 12h (S20), 24h (S10) and $48 \mathrm{~h}$ (S0) respectively. There was no significant difference between groups in the first 6 hours after the onset of stress $(P>0.05)$. The activity of LZM in experimental groups were higher than that in control group between $12 \mathrm{~h}$ and $48 \mathrm{~h}$, all of them returned to normal in $96 \mathrm{~h}$ (Figure 3-A).

The ALP activity of each group showed a trend of increasing first and then decreasing with the prolongation of stress time. There was no significant difference in ALP activity between groups at the same time point $(P>0.05)$. The peaks of S30, S20, S10, S0 occurred at $24 \mathrm{~h}, 24 \mathrm{~h}, 6 \mathrm{~h}$ and $12 \mathrm{~h}$ respectively, with the values of $6.08 \mathrm{king}$ unit/g, 6.30 king unit/g, 5.16 king unit/g and 6.13 king unit/g (Figure 3-B).

The ACP activity of each group increased first and then decreased with the prolongation of stress time. There was no significant difference between groups at the same time point $(P>0.05)$. The peaks of S30, S20, S10, S10 occurred at $48 \mathrm{~h}, 12 \mathrm{~h}, 24 \mathrm{~h}$ and 24 $\mathrm{h}$ respectively, with the values of $104.16 \mathrm{king}$ unit/g, $107.26 \mathrm{king}$ unit/g, $114.98 \mathrm{king}$ unit/g and $114.17 \mathrm{king}$ unit/g. The ACP activity of each group at the beginning of stress ( $1 \mathrm{~h}, 67.03 \sim 86.94 \mathrm{king}$ unit/g) was lower than that at the ending of stress ( $96 \mathrm{~h}$, 86.25 91.67 king unit/g) (Figure 3-C). 

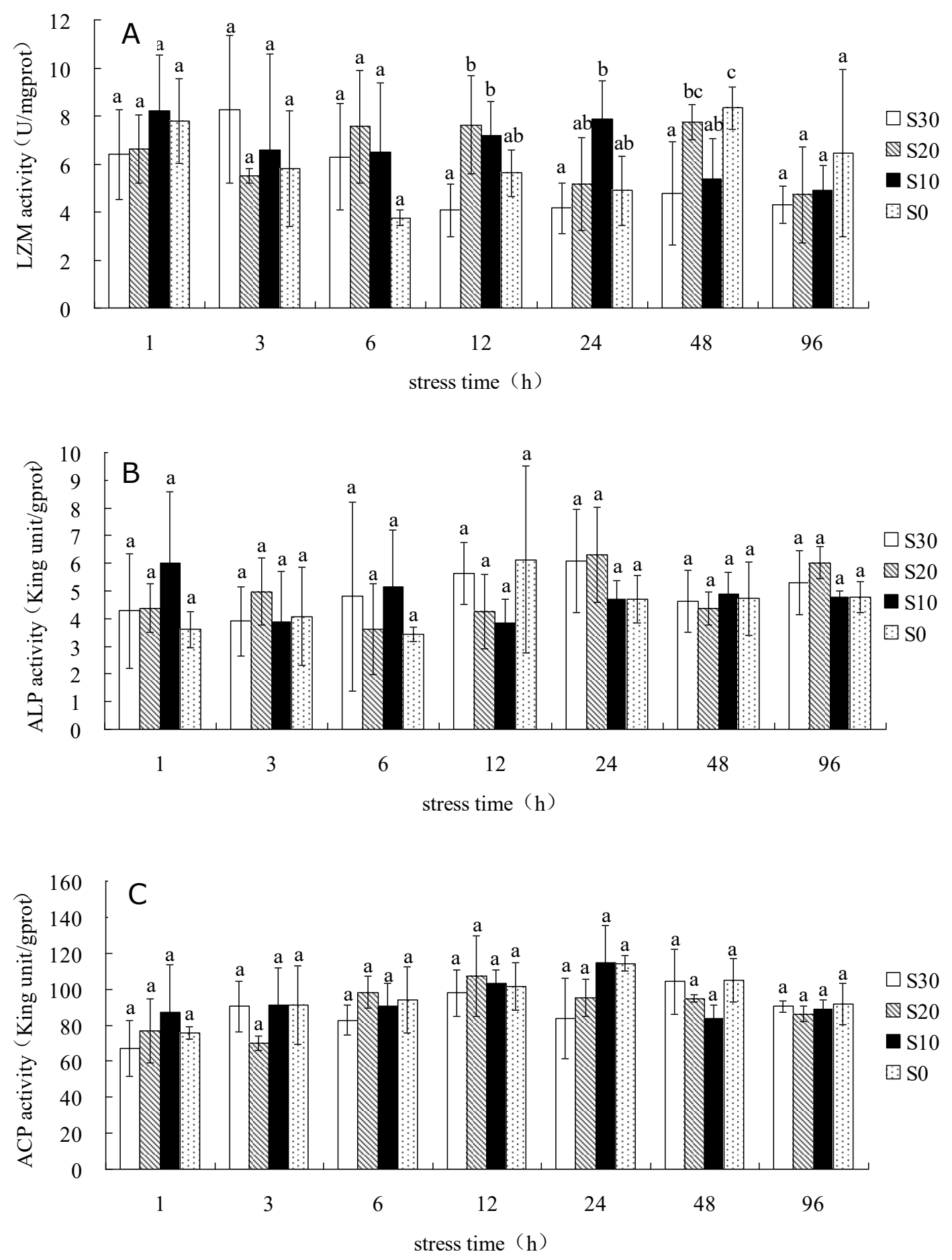

Figure 3 Effect of acute low salinity stress on nonspecific immune enzymes on liver of juvenile $L$. maculates. 


\section{Discussion}

Effects of acute low salinity on behavior and survival rate of juvenile Chinese sea bass

Fish have a certain osmotic pressure regulation ability on water salinity change, and the regulation process is usually accompanied by deep changes in morphology and physiology (McCormick, 2001). When the salinity suddenly changes, the structure of fish gills, liver and other tissues and biochemical indicators such as enzyme activity will change reversibly or fluctuate, accompanied by floating head, abnormal swimming and reduced feeding activities and other adaptive behaviors; but when the fish body is weak or the stress intensity exceeds the endurance capacity of the body, some changes will be irreversible and cause fish death (Zhuang et al., 2011). It can be classified into euryhaline fishes and stenohaline fishes according to the salinity regulation ability. As a euryhaline fish, Chinese sea bass can live in both seawater and fresh water actually, it can maintain osmotic pressure balance in vivo and in vitro within a large salinity range through the regulation function of relevant tissues and organs. In this study, in the face of the maximum salinity change from seawater $(30 \%$ ) to fresh water $(0 \%$ ) , although abnormal behaviors like floating head initially occurred in the experiment fishes, they returned to normal within a few minutes and no death happened, which further indicated that Chinese sea bass had extremely strong salinity regulation ability.

Effects of acute low salinity stress on liver structure of juvenile Chinese sea bass

The liver is the largest digestive organ of the fish body; it combines the synthesis and catabolism of various substances such as sugar, fat and protein. Therefore, the liver is an important target organ for fish exposed to environmental stress and poison. External environmental stress often causes different degrees of histomorphological changes in the liver, usually manifested as hepatocyte enlargement, nucleus pyknosis and migration, vacuolization, abnormal hepatic sinusoids, and even serious irreversible cell fusion, local tissue necrosis, etc. (Strmac et al., 1999). In the control group of S30, the fishes have no obvious pathological structural changes in the whole experimental process; while in the experimental groups, the phenomena such as cell expansion, deformation and vacuolization appeared one after another under salinity stress, and the lower the salinity, the earlier the structural anomaly appeared. When salinity change, in order to adapt to the hypotonic environment, more energy is used to regulate the osmotic pressure in body; the glucose metabolism is carried out in the direction of glycolysis through the regulation of hormones at this time, resulting in a large amount of hepatic glycogen stored in the liver. It is the accumulation of hepatic glycogen that just causes expansion cells and vacuolization (Jin et al., 2015). Also, hepatocyte necrosis rarely occurred in this study, and most of the tissue damage was restored in the later stage, indicating that the juveniles have strong osmotic pressure regulation ability, and have a wide range of salinity adaptation.

Effects of acute low salinity stress on oxidative stress in the liver of juvenile Chinese sea bass

During the culture process, changes in salinity usually cause physiological stress reactions in fish, resulting in excessive reactive oxygen species, causing oxidative damage to the body. The anti-oxidant defense system existing in the fish body can eliminate free radicals in the body, enhance the phagocytic ability of the phagocytic cells and the immune protection function of the body, and maintain the normal physiological activities of the cells and the body. T-AOC is used as an important index to evaluate the body's comprehensive antioxidant capacity, and its size can represent the body's ability to resist free radical metabolism by external stimuli (Zhang et al., 
2004). It is generally believed that SOD is the first to play a role in the process of scavenging reactive oxygen species, which can catalyze the conversion of superoxide in the body into $\mathrm{O}_{2}$ and $\mathrm{H}_{2} \mathrm{O}_{2}$ by disproportionate reaction, which is an important indicator for anti-stress ability of fish (Qu et al., 2017). In addition, When reactive oxygen radicals attack polyunsaturated fatty acids in biofilms in vivo, lipid peroxidation will be triggered and MDA will be produced eventually; therefore, MDA content can indirectly reflect the severity of free radical attack on cells(Liao et al., 2016).In this experiment, the T-AOC and SOD of the liver of juvenile fish showed a trend of increasing first and then decreasing, which was similar to Siganus guttatus (Zhuang et al., 2011), Nibea albiflora (Chen, 2014) and Eleutheronema rhadinum (Zhang et al., 2013). At the beginning of the experiment, the stress reaction of salinity dropped caused the organism to produce a large number of reactive oxygen radicals, so the activities of T-AOC and SOD increased to eliminate excess free radicals and maintain the body's steady state. After a period of time, juveniles adapted to low salt environment, these two indicators fell with the reduction of free radical production. And salinity stress began, a large amount of oxygen free radicals in the body could not be decomposed in time, causing lipid peroxidation, and a large amount of MDA was produced by metabolism. With the increase of antioxidant enzyme activities such as SOD, excess free radicals in the body were eliminated, and MDA content was eliminated accordingly. All antioxidant indexes in the experimental groups were kept at a low level eventually, indicating that juvenile Chinese sea bass could adapt to various salinity conditions, which was consistent with its euryhaline characteristics.

Effects of acute low salinity stress on liver non-specific immunity of juvenile Chinese sea bass

The non-specific humoral immune system is the first line of defense against external stimuli. LZM, as a humoral immune factor, hydrolyzes peptidoglycan in the cell wall of Gram-positive bacteria to lyse cells, thereby killing pathogenic microorganisms and playing an important defense function (Li et al., 2001). Fevolden et al (1993). believed that LZM activity could be used as a signal of fish stress. Studies have shown that when the salinity is lowered, the LZM activity in the fish body will increase first and then decrease. For example, when the salinity of seawater decreased from 30 to 10 and 5, the activity of LZM in the serum of Sebastes schlegeli rose to a peak after 24 hours of treatment, and then gradually decreased (Wang et al., 2005); Paralichthys olivaceus from salinity when 30 was lowered to 20, LZM gradually decreased after reaching the highest activity on the $5 \mathrm{~d}$ (Wei et al., 2003); When Rachycentron canadum was transferred to a low salinity environment, serum LZM activity increased on the $7 \mathrm{~d}$ and fell to the normal level on the $14 \mathrm{~d}$ (Feng et al., 2007). This study was similar to the above findings, after experiencing low salinity stress, the fish produce a stress and protective response, accompanied by an increase in LZM activity to enhance the body's immunity; as time goes on, the body adapts to the new osmotic pressure environment, and the LZM activity gradually returns to normal with the disappearance of stress. Therefore, LZM plays an important role in the non-specific immunity of juvenile Chinese sea bass.

ALP and ACP play an important role in the metabolism of tissues and non-specific immunity as lysosomal enzymes. Salinity stress usually causes aging or death of cells and organelles. It needs phosphatase to remove it. At this time, ALP and ACP activities increase, and the body's immunity is appropriately increased. Studies have shown that when the salinity is reduced, the ALP and ACP activities of the fish such as Scortum barcoo (Zhang et al., 2011) and Pleuronectes yokohama (Cui et al., 2017) show a trend of increasing first and then decreasing. The trend of liver phosphatase activity

The Israeli Journal of Aquaculture - Bamidgeh • IJA.73.2021.1115060 
in this experiment fish was similar to the above results. And at the end of the experiment, ALP and ACP activities were all higher than the initial values, indicating that low salinity stress would cause stress to juvenile Chinese sea bass, which stimulated a certain degree of immune response. In addition, during low salinity stress, there was no significant difference in ALP and ACP activity between experimental groups, experimental group and control group at the same time point $(P>0.05)$, indicating that juvenile Chinese sea bass had strong regulation ability. Low salinity stress did not cause severe tissue damage and organelle destruction.

\section{Conclusions}

Studies have shown that acute low salinity stress has little effect on liver structure and physiological and biochemical indexes of juvenile Chinese sea bass. The juvenile Chinese sea bass has strong low salt tolerance and adaptability, and the seed can be fully adapted to freshwater aquaculture environment after desalination. It should be noted that when the salinity of the water suddenly drops to a lower level, the liver structure and some physiological indexes of the juvenile fish will fluctuate greatly in a short period of time due to stress, so it should be gradually diluted in the actual breeding process to avoid acute response. At the same time, the salinity tolerance of fish with different specifications is also different, and further research is needed.

\section{Acknowledgements}

This research was supported by the Central Public-interest Scientific Institution Basal Research Fund, South China Sea Fisheries Research Institute, CAFS (NO.2018ZD01); Fund of Guangdong Provincial Key Laboratory of Fishery Ecology and Environment

(FEEL-2019-11; FEEL-2020-5) ; the Guangzhou Municipal Science and Technology Project (NO. 201906010028).

\section{References}

Chen Q.K., 2014. Effects of low salinity stress on antioxidant and immune parameters in serum of juvenile Nibea albiflora. Marine Fisheries, 36(6):516-522. doi: 10.13233/j.cnki.mar.fish.2014.06.006.

Cui Q.J., Chen B., Qiu L.H., Fu X., Yang B.X., Han Y.Z. and Jiang C., 2017. Influence of Low Salinity Stress on the Gill $\mathrm{Na}^{+} / \mathrm{K}^{+}$-ATPase, Liver Antioxidase and NonSpecific Immune Enzyme in Juvenile Pleuronectes yokohama. Journal of Guangdong Ocean University, 37(6):26-32. doi: 10.3969/j.issn.1673-9159.2017.06.005

Feng J., Xu L.W., Lin H.Z., Guo Z.X. and Guo G.X., 2007. Effects of salinity on growth and several immune parameters of juvenile cobia, Rachycentron canadum. Journal of Fishery Sciences of China, 14(1):120-125. doi: 10.3321/j.issn:10058737.2007.01.017.

Jin X.Z., Chen Q.K., Ye K., Gong S.Q., Wang Z.Y. and Xie Y.J., 2015. The Histological Studies on Some Organs of Large Yellow Croaker, Larimichthys crocea Reared in Low Salinity Water. Journal of Jimei University (Natural Science), 20(2):9097. doi: 10.3969/j.issn.1007-7405.2015.02.002

Liao Y.L., Zhang C.J., Peng S.M., Gao Q.X. and Shi Z.H., 2016. Effects of salinity on activities of liver antioxidant enzymes and plasma lysozyme of Epinehelus moara. Journal of Shanghai Ocean University. 25(2):169-176. doi: $10.12024 /$ jsou. 20150401427

Li L. and Wu Z.H., 2001. Advances in research on humoral immunity of fish. Marine Sciences, 25(11):20-22. doi: 10.3969/j.issn.1000-3096.2001.11.007

Liang J.W., Zhu J.H. and Huang C.L., 2015. Bass bass alkalization culture technology. Ocean and fishery. (3):50-51. doi: CNKI:SUN:HYUY.0.2015-03-027 
Ministry of Agriculture and Rural Fisheries and Fisheries Administration, National Aquatic Technology Extension Station, China Fisheries Society, 2020. 2020 China Fishery Statistical Yearbook. China Agriculture Press, Beijing. 22pp.

Ou Y.J., Liu Q.Q., Wen J.F., Li J.E. and Li H., 2018. The effects of acute low temperature stress on liver, muscle and gill tissues of juvenile Eleutheronema tetradactylum, 37(5):53-59. doi: 10.14108/j.cnki.1008-8873.2018.05.008

Ou Y.J., Chen S.X., Wang P.F., Li J.E., Wen J.F., Wang W. and Xie M.J., 2017. Study on oxidative stress response and physiological metabolism related indices of Trachinotus ovatus under hypoxia stress. South China Fisheries Science, 13(3):120124. doi: 10.3969/j.issn.2095-0780.2017.03.016

Sun M.L., Jiang Z.Q., Jang J.L. and Wang L.P., 2017. Effects of low salt stress on enzyme activity, tissue structure and expression of immune genes in the liver of juvenile Takifugu rubripes. Hebei Fisheries, (4):1-4. doi: 10.3969/j.issn.10046755.2017.04.001

Wang X.J., Zhang X.M. and Li W.T., 2005. Effects of salinity on the non-specific immuno-enzymetic activity of Sebastes schlegeli. Marine Fisheries Research, 26(6):17-21. doi: 10.3969/j.issn.1000-7075.2005.06.004

Wei R., Zhang S.C., Wang C.F., Liu X.Z. and Jiang G.H., 2003. Effects of changes in salinity on nonspecific immune function of Japanese flounder Paralichthys olivaceus. Advances in Marine Science, 21(2):209-213. doi: 10.3969/j.issn.16716647.2003.02.011

Zhang C.L., Hu J.F., Wang P.W., Wang G.T., Liu G.Q., Yu S.F. and Han H.F., 2004. Effects of Benzo(a) Payrene on T-AOC in Liver of Carassius auratus. Journal of Environment and Health. 21(5):325-326. doi: 10.3969/j.issn.1001-5914.2004.05.022 Zhuang P., Wang Y., Zhang L.Z. and Zhao F., 2011. The Effects of Ambient Salinity Decrement on Survival and the Activity of Antioxidant Enzymes in Livers of Siganus guttatus. Journal of Fudan University (Natural Science), 50(3):366-372. doi: 10.15943/j.cnki.fdxb-jns.2011.03.003.

Zhang Q.X., Zhang T., Hou J.L., Yang G., Yang Y., Huang X., Liu J.Y. and Zhang L.Z., 2013. Effects of salinity on activities of gill $\mathrm{Na}^{+} / \mathrm{K}^{+}$-ATPase and liver antioxidase in juvenile Eleutheronema rhadinum. Marine Fisheries, 35(3):324-330. doi: 10.3969/j.issn.1004-2490.2013.03.010

Zhang L.G., An L., Song D., Dun X.S. and Fu P.S., 2011. Effect of Salinity on Activity of Three Immune Factors of Juvenile Scortum barcoo. Journal of Hydroecology, 32(6):110-114. doi: 10.3969/j.issn.1003-1278.2011.06.021

Fevolden S.E. and Roed K.H., 1993. Cortisol and immune characteristics in rainbow trout (Oncorhynchus mykiss) selected for high or low tolerance to stress. Journal of Fish Biology, 43(6): 919-930. doi:10.1111/j.1095-8649.1993.tb01166.x

McCormick S.D., 2001. Endocrine control of osmoregulation in teleost fish. American Zoologist. 41(4):781-794. doi:10.1093/icb/41.4.781

Strmac M. and Braunbeck T., 1999. Effects of triphenyltin acetate on survival, hatching success, and liver ultrastructure of early life stages of zebrafish (Danio rerio). Ecotoxicol Environ Saf, 44(1):25-39. doi: 10.1006/eesa.1999.1781 